\title{
Article
}

\section{Tensile and fatigue failure of 3D printed parts with continuous fibre reinforcement}

\author{
Brooks, Hadley Laurence
}

Available at http://clok.uclan.ac.uk/17995/

Brooks, Hadley Laurence ORCID: 0000-0001-9289-5291 (2017) Tensile and fatigue failure of 3D printed parts with continuous fibre reinforcement. International Journal of Rapid Manufacturing, 6 (2/3). pp. 97-113. ISSN 17578817

It is advisable to refer to the publisher's version if you intend to cite from the work. http://dx.doi.org/10.1504/IJRAPIDM.2017.10003068

For more information about UCLan's research in this area go to http://www.uclan.ac.uk/researchgroups/ and search for < name of research Group>.

For information about Research generally at UCLan please go to http://www.uclan.ac.uk/research/

All outputs in CLoK are protected by Intellectual Property Rights law, including Copyright law. Copyright, IPR and Moral Rights for the works on this site are retained by the individual authors and/or other copyright owners. Terms and conditions for use of this material are defined in the policies page.

\section{CLoK}

Central Lancashire online Knowledge www.clok.uclan.ac.uk

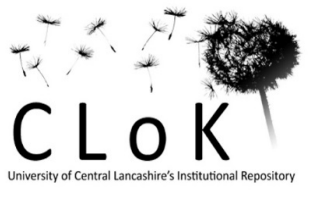


'This article is a revised and expanded version of a paper entitled [Dramatically Increasing the Mechanical Properties of 3D Printed Parts via Continuous Fibre Reinforcement and Coatings] presented at $\left[14^{\text {th }}\right.$ Rapid Prototyping, Design and Manufacturing, Loughborough, $16^{\text {th }}$ December 2015].'

Tensile and Fatigue Failure of 3D Printed parts with Continuous Fibre Reinforcement

\begin{abstract}
This paper introduces a design methodology used to integrate continuous fibre reinforcement into AM polymer parts with the aim of improving their mechanical properties. Tensile and low cycle fatigue testing of reinforced parts is carried out for a range of load conditions and strain rates

Physical testing showed that it was possible to improve the strength of parts by $400 \%$ and cycles to failure by $42,800 \%$ with the addition of $4 \%$ carbon by weight. Logarithmic load/cycle relationships were found also samples showed significant variability in the number of cycles to failure. No correlation between the density of the polylactic acid (PLA) infill and the tensile strength or low cycle fatigue life.

Access holes used to thread the fibre into the reinforcement channels were identified as stress concentrators initiating cracks in the PLA and separation of the reinforcement from the PLA part.
\end{abstract}

KEYWORDS: Carbon fibre, Fatigue, Mechanical properties, Failure modes, Additive manufacturing.

\title{
1. INTRODUCTION
}

The term additive manufacturing (AM) encompasses a diverse set of technologies that share the principle of building parts in a layer based fashion (Gibson et al., 2010). This build strategy has the advantage of producing parts with complex geometries without the need for tooling. The AM sector continues to grow rapidly as new applications are found and knowledge of design for AM spreads. The desktop 3D printing market is one of the fastest growing segments in the AM sector with fused filament fabrication (FFF) printers found in schools, businesses and hospitals (Wohlers, 2016). Open source development of FFF printers has resulted in low cost machines and software with a wide range of capabilities. A study by Tymrak et al. (2014) shows parts made from well-tuned open-source desktop machines and generic materials have mechanical properties comparable to proprietary systems.

The inhomogeneous nature of FFF parts results in parts with approximately $80 \%$ the strength of injection moulded or machined parts of the same polymer (Montero et al., 2001, Ahn et al., 2002, Hambali et al., 2012, Ziemian et al., 2012). Despite this FFF parts exhibit excellent 
strength-to-weight ratios in many applications by incorporating light-weight cellular structures in areas of low stress and topologically optimised geometries (Lu et al., 2014, Villalpando et al., 2014, Rodríguez et al., 2003, Gardan and Schneider, Brackett et al., 2011).

For applications requiring higher strength or stiffness, conventional thermoplastics such as acrylonitrile butadiene styrene (ABS) or polylactic acid (PLA) are not adequate. Introducing reinforcement fibre into the part is an effective way to extend the capabilities of FFF machines for higher load applications. Short fibres can be mixed into the polymer feedstock and deposited in the usual way. The low volume fraction and pull out strength of the short fibres results in minor gains in strength and stiffness whilst toughness is often reduced (Ning et al., 2015, Mahajan and Cormier, 2015). FFF machines capable of depositing continuous fibre reinforcement are rare however studies suggest continuous fibre reinforced parts achieve significantly increased specific strength, stiffness and toughness (Namiki et al., 2014, Van Der Klift et al., 2015). One drawback of depositing continuous fibre reinforcement during the layered manufacturing process is that the fibres are confined to the build layers, preventing true three dimensional reinforcement.

Recent research has shown that designing reinforcement channels into AM parts, and adding continuous reinforcement in a post-build process, dramatic increases in mechanical properties are achievable regardless of the build orientation of the part (Brooks and Molony, 2016, Brooks and Molony, 2015). This method, briefly explained in the next section, also has the advantage of working with all AM technologies. Subsequently these types of parts will be referred to as reinforced FFF parts.

\subsection{Reinforced FFF parts}

The aim of this methodology is to design channels within the parts that may be filled with load bearing uniaxial continuous reinforcement. The design process can be summarised according to Figure 1.

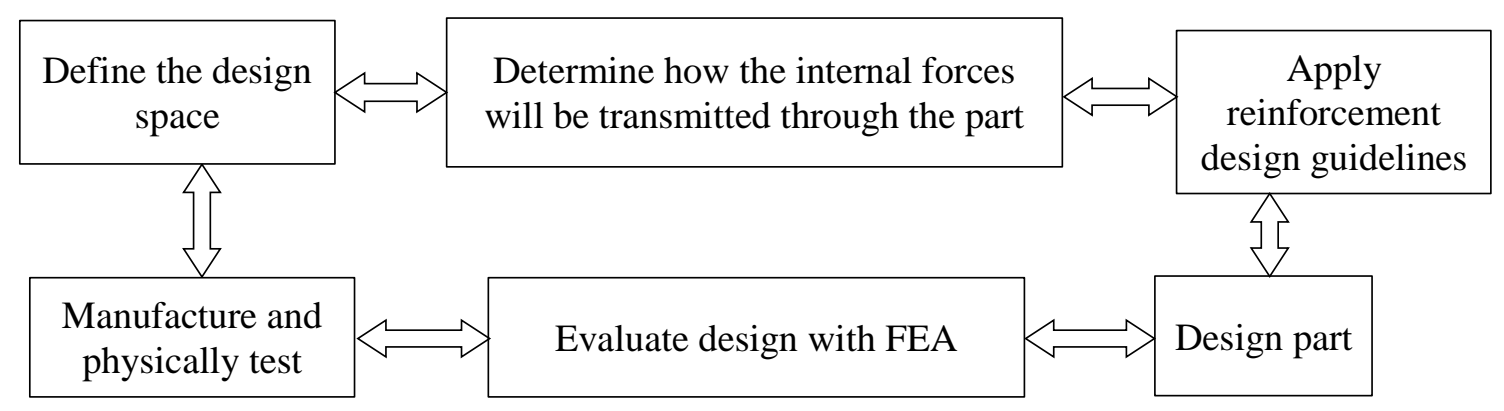

Figure 1: Schematic of the design process.

In this process the load carrying material is assumed to be the reinforcement, whilst the printed part is considered a preform that holds the reinforcement in place. Assuming the reinforcement is much stiffer than the polymer part material $(\mathrm{Er}>\mathrm{Em})$ it will take a proportionately higher percentage of the load, as demonstrated by applying the rule of mixtures to the Voigt model for axial loading [8].

$$
E_{c}=\sigma_{c} / \varepsilon_{c}=\frac{(1-f) \sigma_{m}+f \sigma_{r}}{\left(\sigma_{r} / E_{r}\right)}=(1-f) E_{m}+f E_{r} \quad \text { Equation (1) }
$$


The reinforcement design guidelines were developed in parallel with experimental testing and can be found in previous works (Brooks and Molony, 2016, Brooks and Molony, 2015). Figure 2 shows the outcome of applying the design methodology to a pulley housing.
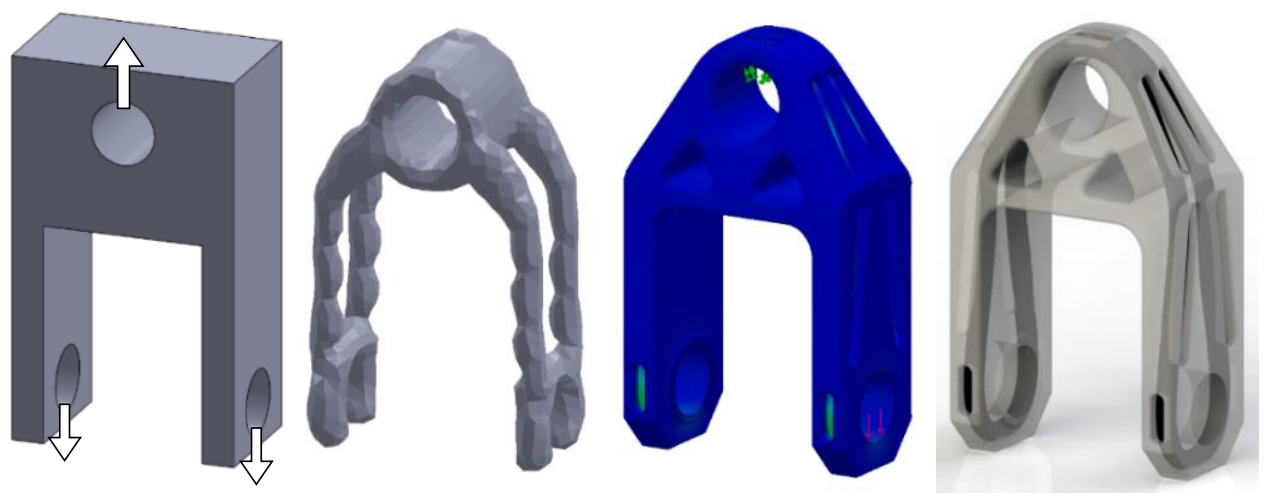

Figure 2: Evolution of the reinforced pulley from left to right: volumetric design space, topological optimisation, FEA of composite, final iteration after first physical tests.

Figure 3 shows the load-displacement curves for PLA pulley housings from a previous study (Brooks and Molony, 2016) with and without carbon fibre reinforcement with a strain rate of $2.5 \mathrm{~mm} / \mathrm{min}$. The reinforcement resulted in a 4,689\% increase in tensile strength and a 2,212\% increase in elongation to failure over the unreinforced part. The reinforced part exhibited steady deformation around the holes with minor cracks forming in the polymer/resin at around $2 \mathrm{~mm}$ of elongation (3.3\% strain). Final failure of the reinforcement occurred near the holes.

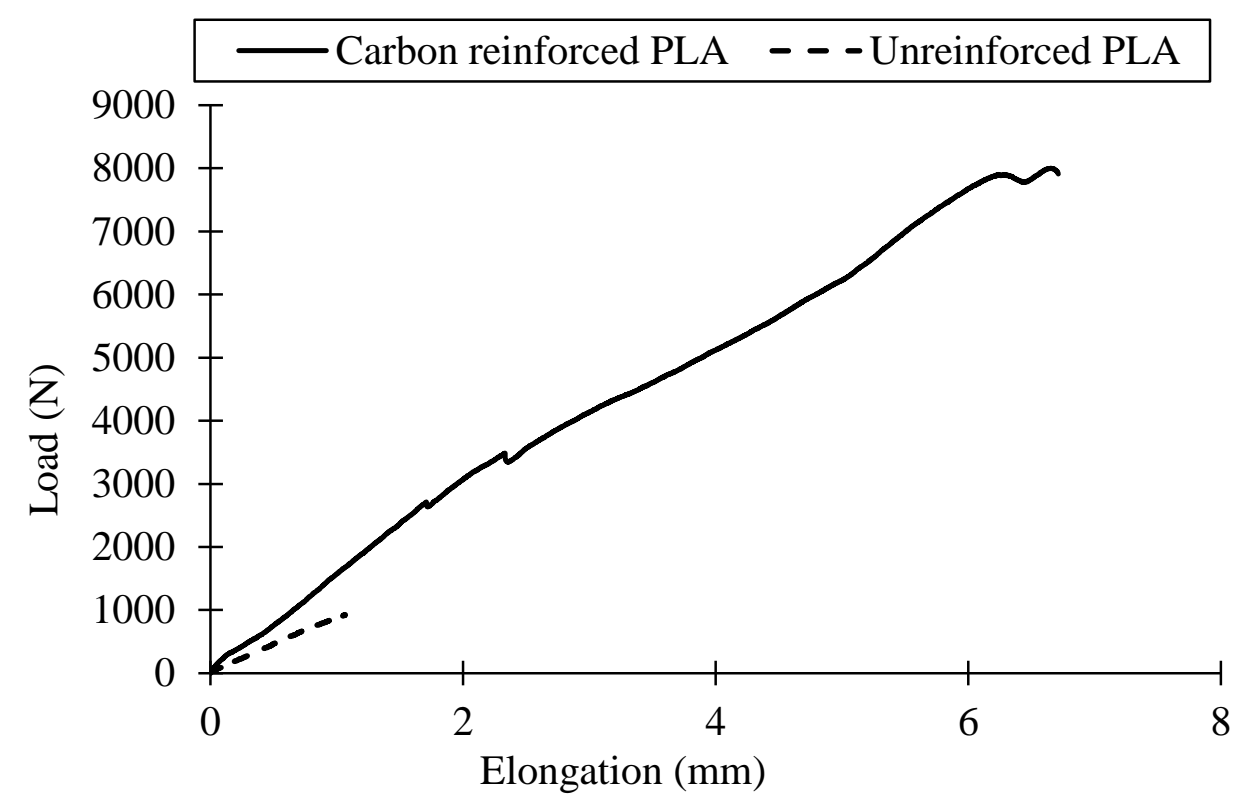

Figure 3: Load-elongation curves for PLA pulley housings with and without carbon reinforcement.

Many questions remain as to how the reinforced parts will perform in a variety of loading conditions and how repeatable the manufacturing process is. The aim of this study is to further investigate the tensile and low cycle fatigue failure of these parts for a variety of strain rates. 
In order to provide a base for the interpretation of the results a short review of current literature into the failure of FFF parts and carbon fibre reinforced plastics (CFRP) is given below.

\subsection{Failure of FFF parts}

There have been numerous studies into the tensile and compressive strength of FFF parts (Afrose et al., 2014, Ahn et al., 2002, Gardan and Schneider, Hambali et al., 2012, Montero et al., 2001, Rodriguez et al., 2000, Rodríguez et al., 2003, Sood et al., 2010, Tymrak et al., 2014, Villalpando et al., 2014, Ziemian et al., 2012, Bellehumeur et al., 2004, Sun et al., 2008). These studies found a wide range of factors impact on the strength of the parts including: material, extrusion temperature, layer heights, infill strategy, infill density, infill angle, number of shells, road width, air gap, strain rate, sample geometry and sample size. The variability in the way FFF parts are printed makes it difficult to directly compare results between the studies. However some commonly observed relationships are: higher infill densities lead to higher part strengths, longitudinal fill patterns are stronger than transverse fill patterns and parts built in the $x-y$ plane (horizontally) are much stronger than parts built in the $\mathrm{z}$ or vertical plane. The most common tensile failure modes are layer delamination, fibre delamination or tensile fibre (also known as road, filament or bead) failure.

Failure due to fatigue or impact loads have received less attention. Recent work into the fatigue of ABS and PLA FFF parts revealed logarithmic S-N curves where lower loads resulted in higher cycles to failure (Afrose et al., 2015, Lee and Huang, 2013, Ziemian et al., 2015). Infill angle and build orientation were found to have the similar effects on fatigue life as those found in tensile tests. Impact testing of FFF parts also confirms anisotropic material properties with longitudinal infill patterns and higher infill densities having superior strength and impact resistance over transverse infill patterns and lower infill densities (Es-Said et al., 2000, Sood et al., 2010).

\subsection{Failure of CFRP parts}

Due to the importance of carbon fibre composites in safety-critical industries such as transportation, the tensile failure modes of fibre reinforced composites have been studied extensively (Bhat et al., 2008, Hashin and Rotem, 1973, Mallick, 2007). The dominant tensile failure modes of CFRPs are fibre pull out, fibre/matrix fracture and interlayer delamination (Mallick, 2007, Zweben, 1968, Batdorf, 1982).

Unidirectional CFRPs are known to have excellent high cycle fatigue (HCF) properties (Hashin and Rotem, 1973, Harris, 2003, Mallick, 2007, Harik et al., 2002). Damage accumulation is relatively slow with few fibres breaking in the early cycles. Over time small cracks and voids in the matrix grow and coalesce leading to matrix failure and subsequent fibre fracture. Carbon fibre composites with thermosets are often found to have superior fatigue life than thermoplastics due to higher fibre bond strength (Harris, 2003).

Deterioration of mechanical properties of CFRPs can be severe when subjected to large low cycle fatigue (LCF) loads. High levels of strain result in a high number of fibre breakages in the early cycles. While HCF of unidirectional composites are considered in many structural designs (e.g. shafts, flywheels beams etc.), the LCF limit is considered in the reliability estimates for safety, insurance risks and life cycle costs (Harik et al., 2002). 


\section{METHOD}

This section outlines the method for the tensile and LCF testing of conventional and reinforced FFF parts. A dog bone sample shape was chosen to allow for better comparison with previous studies of unreinforced and reinforced AM parts.

\subsection{Specimen design}

The dog bone (DB) specimens have been designed to comply with the BS 2782-3: 320C. This geometry was chosen to allow for the slight increase in thickness required for the reinforcement channel. The reinforcement channel is a continuous loop aligned with the direction of pull in the narrow section (Figure 4). Access holes are positioned around the sides of the specimens to allow the carbon fibre tows to be threaded. The unreinforced specimens share the same geometry but with the reinforcement channels and access ports removed.
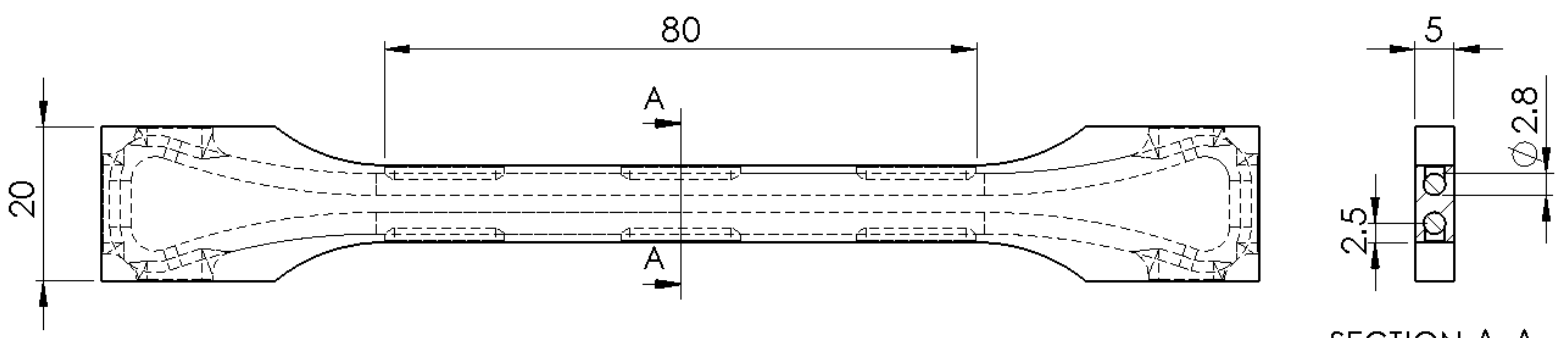

SECTION A-A

Figure 4: Dog bone (DB) geometry showing reinforcement channels.

A static finite element analysis of the design was carried out as a preliminary check of the design. One tab of the sample was fixed while a $1000 \mathrm{~N}$ longitudinal load was applied to the opposite tab. The cross-section of the composite carbon fibre reinforcement was calculated to be $25 \%$ of the channel cross-section, based on two loops of $12 \mathrm{~K}$ carbon fibre and a $60 \%$ volume fraction. The material properties for PLA and $0^{\circ}$ carbon fibre composite were assumed to be isotropic with ideal bonding between the two. Figure 5 shows a cross-section of the FEA stress distribution. The higher stiffness of the reinforcement results in high levels of stress contained within the reinforcement while the PLA experiences negligible stress.

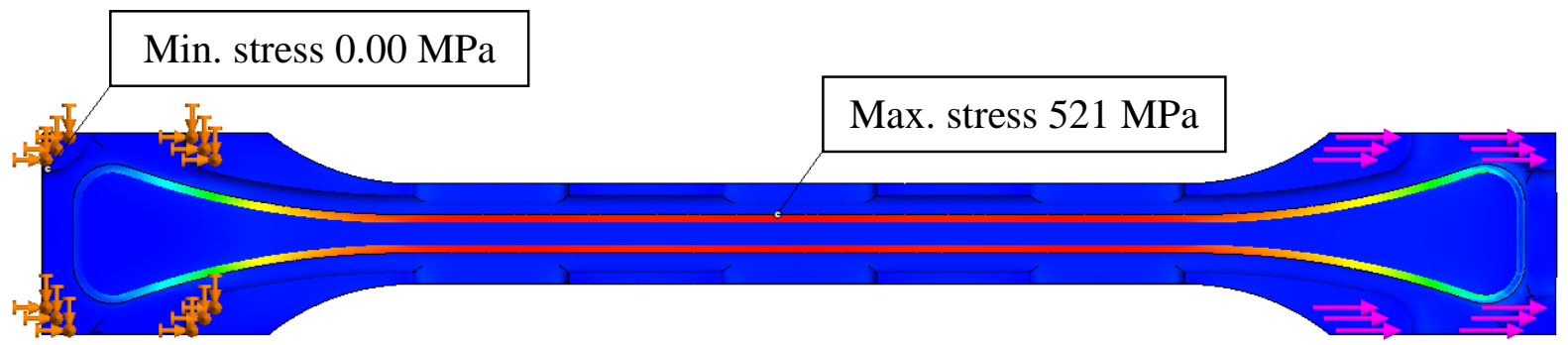

Figure 5: FEA stress distribution of the centre of a reinforced sample showing the highly loaded carbon fibre reinforcement.

The maximum stress of $521 \mathrm{MPa}$ lies in the narrow part of the sample and is significantly lower than the ultimate tensile stress of $0^{\circ}$ single tow carbon fibre composites which is approximately $2950 \mathrm{MPa}$. 


\subsection{Manufacture}

All samples were printed with eSUN natural PLA filament on a MakerGear M2 with $0.15 \mathrm{~mm}$ layer heights, 3 solid shell layers and $\pm 45^{\circ}$ rectilinear infill. The reinforced samples have a higher surface area and because the parts are printed with solid shells they weigh significantly more than the unreinforced samples, if equal infill densities are used. For this reason the unreinforced samples were printed with higher infill densities in order to mitigate the variation in sample weights.

High density reinforced DB samples were also printed to allow a comparison between reinforced parts with high and low infill densities. In addition, pulley housings as shown in section 1.1 were printed to see if the results from the dog bones are transferrable to parts with significantly different geometries. Table 1 summarises the build variations between the sample groups. Note that the reinforced DB with $25 \%$ infill contained more PLA than the unreinforced DB with $50 \%$ infill.

Table 1. Tensile and fatigue sample properties.

\begin{tabular}{|r|c|c|c|c|c|c|}
\hline \multirow{2}{*}{ Sample group } & \multirow{2}{*}{$\begin{array}{c}\text { Infill } \\
\text { density } \\
(\%)\end{array}$} & \multicolumn{4}{|c|}{ Weight (g) } & FFF build \\
\cline { 3 - 6 } & PLA & Carbon fibre & Epoxy & Totalion \\
\hline Unreinforced DB & 50 & 7.20 & - & - & 7.20 & Horizontal \\
\hline $\begin{array}{r}\text { Reinforced low } \\
\text { density DB }\end{array}$ & 25 & 8.41 & 0.50 & 1.69 & 10.6 & Horizontal \\
\hline $\begin{array}{r}\text { Reinforced high } \\
\text { density DB }\end{array}$ & 90 & 9.91 & 0.50 & 1.69 & 12.1 & Horizontal \\
\hline Reinforced pulley & 25 & 13.70 & 0.43 & 0.86 & 15.0 & Vertical \\
\hline
\end{tabular}

Tansome 12k H2550 fibre tow was threaded through the reinforcement channels twice resulting in approximately $500 \mathrm{mg}$ of carbon fibre for each DB sample and $431 \mathrm{mg}$ for the pulley samples. Low viscosity epoxy laminating resin (EL2 from Easy Composites ${ }^{\mathrm{TM}}$ ) was used to bond the reinforcement within the channels. Excess resin was then allowed to drain from the part before being cured in an oven at approximately $50^{\circ} \mathrm{C}$.

\subsection{Testing}

All samples were tested on a Testometric FS100SCCT universal testing machine. At least three samples were used for each combination of load and strain rate. The test schedule is shown in table 2 .

Table 2. Test schedule with strain rates and percentage of ultimate tensile load (UTL) combinations for each sample group.

\begin{tabular}{|r|c|c|c|}
\hline \multirow{2}{*}{ Sample group } & \multicolumn{3}{|c|}{ Strain rate } \\
\cline { 2 - 4 } & $25.4 \mathrm{~mm} / \mathrm{min}$ & $127 \mathrm{~mm} / \mathrm{min}$ & $254 \mathrm{~mm} / \mathrm{min}$ \\
\cline { 2 - 4 } & \multicolumn{3}{|c|}{$\%$ of Ultimate tensile load } \\
\hline Unreinforced DB & 100,80 & - & 100,80 \\
\hline Reinforced low density DB & 100,90 & 100,85 & $100,90,85,80$ \\
\hline Reinforced high density DB & 90 & - & - \\
\hline
\end{tabular}




\begin{tabular}{|r|c|c|c|}
\hline Reinforced pulley & - & - & $100,90,80$ \\
\hline
\end{tabular}

The tensile tests were carried out first to determine an average ultimate tensile load (UTL) for each strain rate.

The maximum load for the unreinforced LCF tests was 0.8UTL with a minimum load of zero. The maximum load for the reinforced LCF tests varied between 0.8 and 0.9UTL with an alternating load of $0.2 \mathrm{UTL}$. The lower alternating load for the reinforced samples was required to reduce the cycle time of the relatively long-lived composite samples. Figure 6 shows a typical displacement time curve for a reinforced and unreinforced LCF sample including the initial ramp up phase. The actual time taken for each cycle varied with the maximum force being tested in each sample group. For each test, data was recorded for force $(\mathrm{N})$, displacement $(\mathrm{mm})$, and time (s).

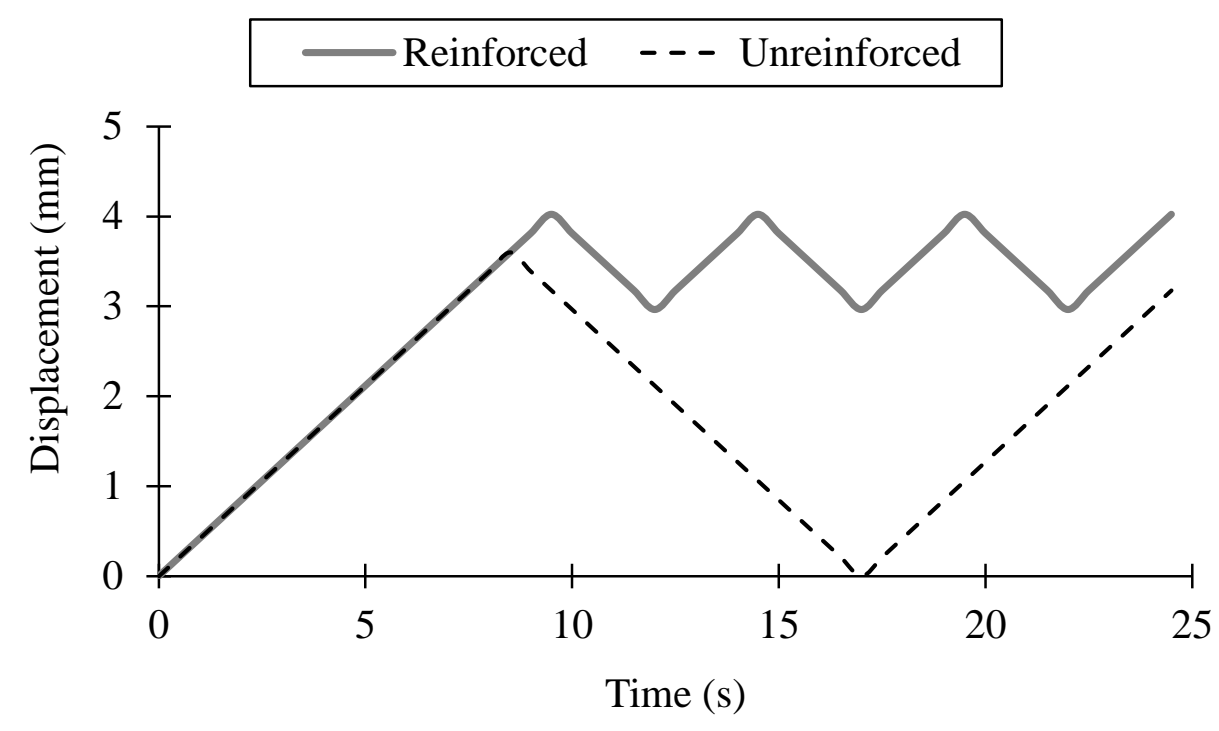

Figure 6: Displacement profile for samples with a $25.4 \mathrm{~mm} / \mathrm{min}$ strain rate. Total cycle time varies for each cycle.

\section{RESULTS}

\subsection{Unreinforced FFF samples}

The unreinforced PLA tensile samples produced deformation curves with little plastic deformation which is typical for hard brittle polymers. Figure 7 shows force/elongation curves for strain rates of 25.4 and $254 \mathrm{~mm} / \mathrm{min}$. The faster strain rate was found to result in slightly higher UTLs but lower elongation to failure. 


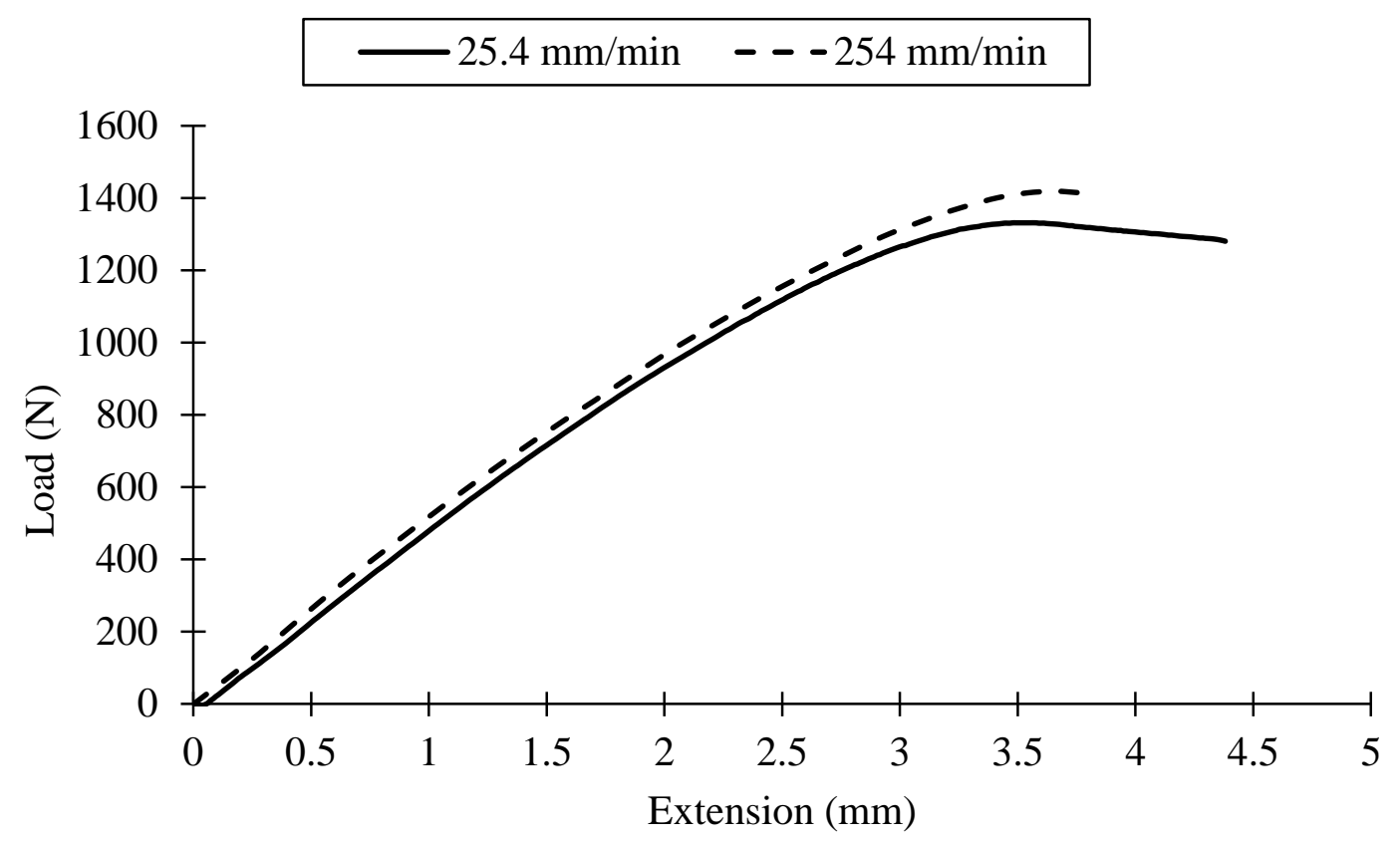

Figure 7: Typical load/elongation curves for unreinforced samples pulled at 25.4 and 254 $\mathrm{mm} / \mathrm{min}$.

The average UTL, elongation to failure and nominal strain energy for samples at both strain rates are shown in Table 3, along with their respective standard deviations. The nominal strain energy was calculated by summing the trapezoidal areas under adjacent data points and dividing by the nominal volume of the samples narrow section. The samples pulled at the lower strain rate had higher nominal strain energies and much higher cycles to failure. Figure 8 shows a typical load/elongation curve for a LCF sample with a maximum load 0.8UTL and a strain rate of $254 \mathrm{~mm} / \mathrm{min}$. All LCF samples showed characteristic hysteresis loops shifting along the elongation axis until final failure.

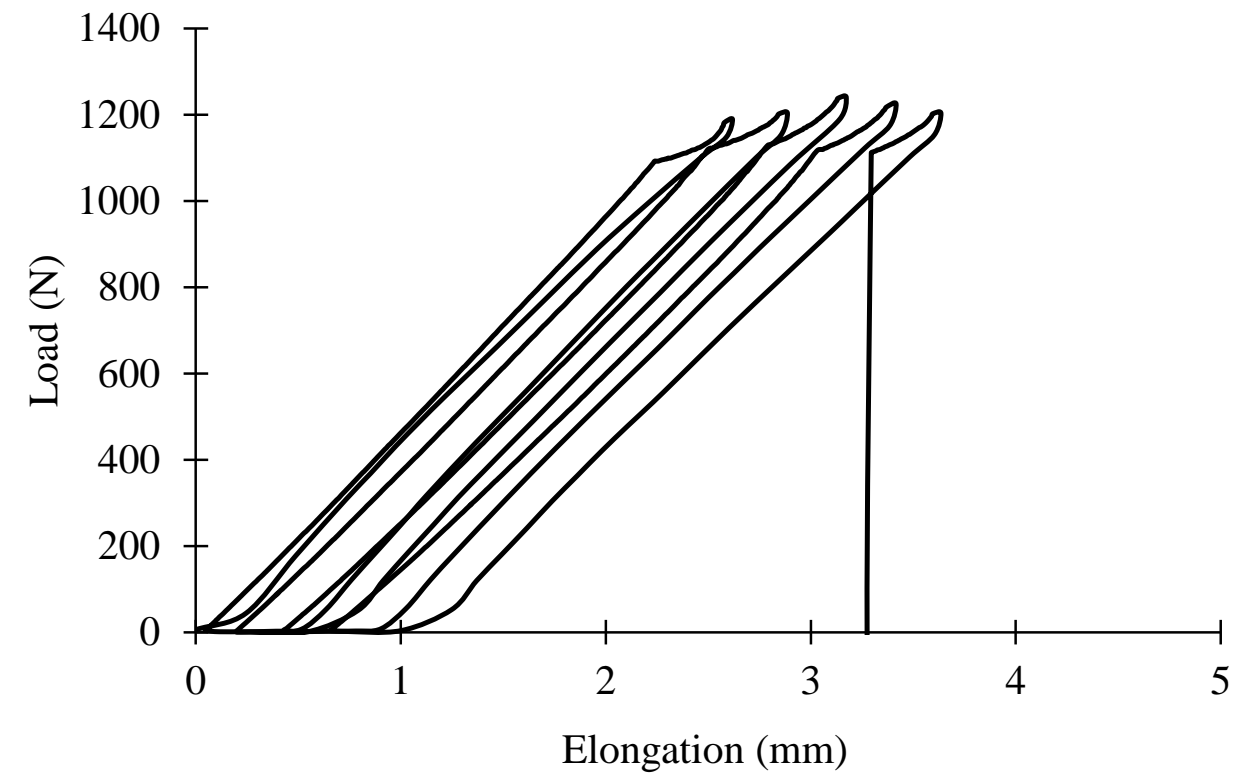

Figure 8: Typical load/elongation curve for a sample with $254 \mathrm{~mm} / \mathrm{min}$ strain rates. 
The UTL, elongation to failure and nominal strain energy data varied with standard deviations from 1.4 to $10 \%$. The number of cycles to failure varied considerably with standard deviations over $30 \%$.

Table 3. Average ultimate tensile load, elongation to failure, strain energy, and cycles to failure for tensile and LCF unreinforced DB samples with corresponding standard deviations in $\%$.

\begin{tabular}{|c|c|c|c|c|c|}
\hline \multirow{2}{*}{$\begin{array}{c}\text { Strain } \\
\text { rate } \\
\mathrm{mm} / \mathrm{min}\end{array}$} & $\begin{array}{c}\text { Average UTL } \\
(\mathrm{N})\end{array}$ & $\begin{array}{c}\text { Average } \\
\text { Elongation } \\
(\mathrm{mm})\end{array}$ & $\begin{array}{c}\text { Nominal strain } \\
\text { energy }\left(\mathrm{kJ} / \mathrm{m}^{3}\right)\end{array}$ & $\begin{array}{c}\text { Average } \\
\text { cycles to } \\
\text { failure }\end{array}$ & $\begin{array}{c}\text { Average } \\
\text { elongation at } \\
\text { failure }(\mathrm{mm})\end{array}$ \\
\hline 25.4 & $1273 \pm 3.0 \%$ & $4.18 \pm 4.0 \%$ & $877 \pm 7.3 \%$ & $55.2 \pm 30 \%$ & $2.87 \pm 5.5 \%$ \\
\hline 254 & $1423 \pm 1.4 \%$ & $3.73 \pm 4.1 \%$ & $778 \pm 3.5 \%$ & $8.00 \pm 47 \%$ & $3.67 \pm 9.9 \%$ \\
\hline
\end{tabular}

\subsection{Reinforced FFF samples}

The reinforced tensile samples failed at significantly higher loads than the unreinforced samples with modest increases in elongation to failure (Figure 9). Higher strain rates were found to lead to lower UTLs, elongation to failure and nominal strain energies.

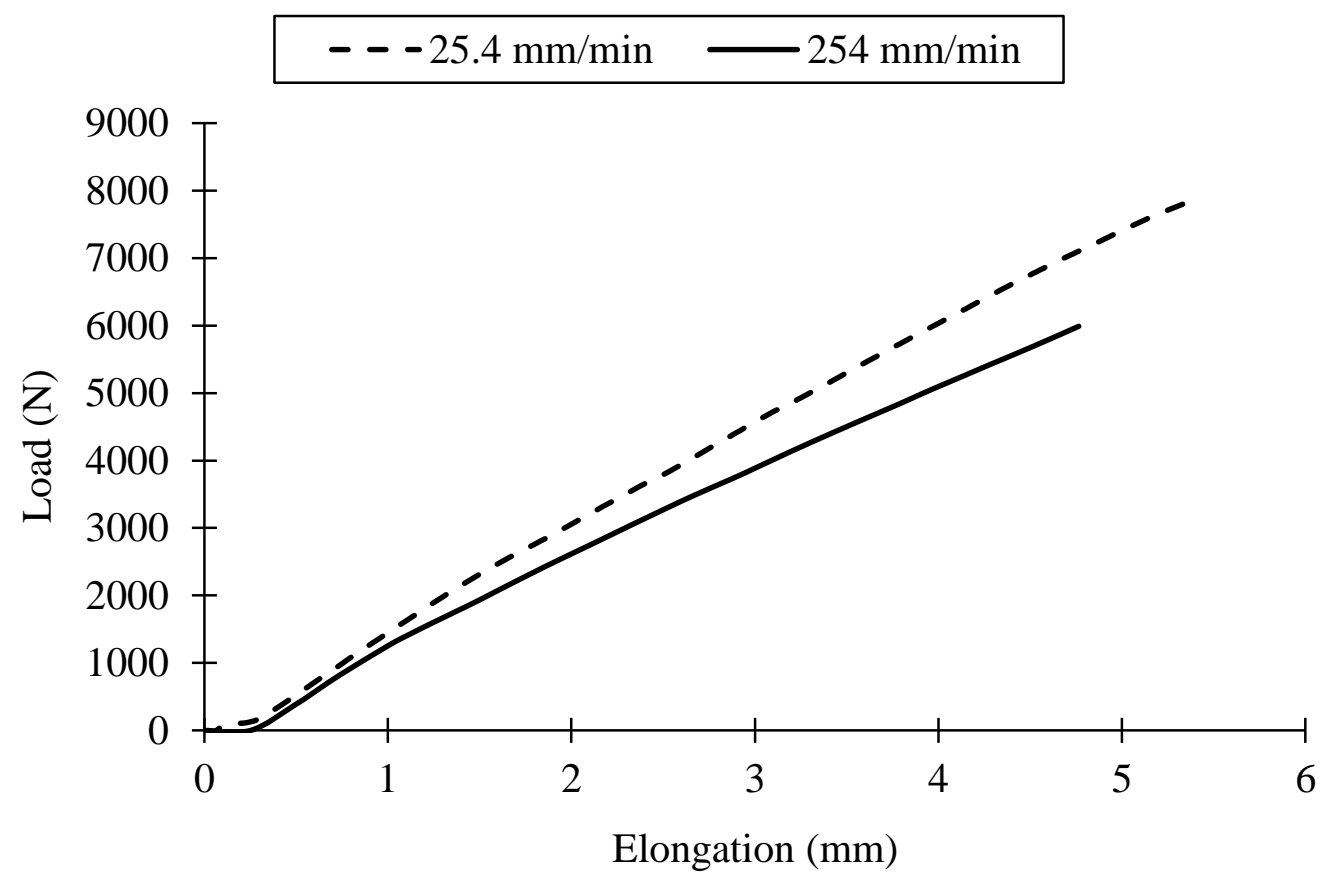

Figure 9: Load/elongation curves for reinforced samples pulled at 25.4 and $254 \mathrm{~mm} / \mathrm{min}$.

In most cases the only visible evidence of damage accumulation before sudden fracture was crazing of the PLA near the ends of the access holes. Figure 10 a) shows a fractured sample after a high strain rate tensile test whilst Figure $10 \mathrm{~b}$ ) shows low strain rate fatigue failure. The high strain rate resulted in the PLA rupturing as the curved reinforcement located in the lower tab straightened. This failure mode was not predicted by the static FEA due to the assumption of ideal bonding. The failure shown in Figure $10 \mathrm{~b}$ ) is characteristic of the majority of LCF failures seen in this study with cracks forming in the PLA near the access holes, gradual delamination of the reinforcement from the PLA and then simultaneous fracture of the PLA and carbon fibre/epoxy. 


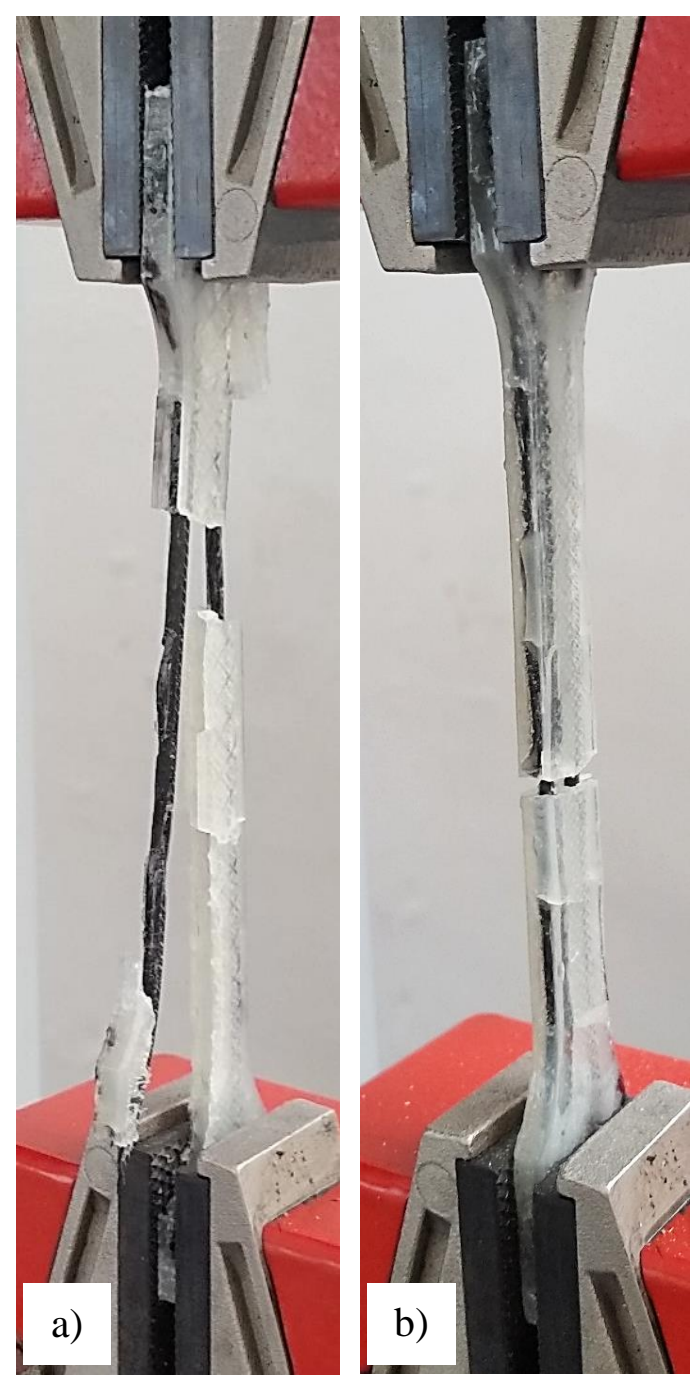

Figure 10: a) Sample after $254 \mathrm{~mm} / \mathrm{min}$ tensile test. b) Sample after $25.4 \mathrm{~mm} / \mathrm{min}$ LCF test.

Table 4 summarises the average UTL, elongation and nominal strain energies for the reinforced sample tensile tests.

Table 4. Average ultimate tensile load, elongation to failure, strain energy, and cycles to failure for tensile and LCF unreinforced DB samples with corresponding standard deviations in $\%$.

\begin{tabular}{|c|c|c|c|}
\hline \multirow{2}{*}{$\begin{array}{c}\text { Strain } \\
\text { rate } \\
\mathrm{mm} / \mathrm{min}\end{array}$} & $\begin{array}{c}\text { Average UTL } \\
(\mathrm{N})\end{array}$ & $\begin{array}{c}\text { Average } \\
\text { Elongation } \\
(\mathrm{mm})\end{array}$ & $\begin{array}{c}\text { Nominal strain } \\
\text { energy }\left(\mathrm{kJ} / \mathrm{m}^{3}\right)\end{array}$ \\
\hline 25.4 & $6593 \pm 14 \%$ & $5.27 \pm 9.8 \%$ & $4648 \pm 21 \%$ \\
\hline 254 & $4496 \pm 38 \%$ & $4.61 \pm 18 \%$ & $3341 \pm 17 \%$ \\
\hline
\end{tabular}

A direct comparison between the 0.8UTL reinforced and unreinforced LCF samples shows the reinforced samples life was 428 times greater (on average), whilst supporting an extra $3073 \mathrm{~N}$ tensile load. 
Figure 11 shows the load/cycle graph for LCF samples with strain rates of 25.4 and 254 $\mathrm{mm} / \mathrm{min}$. Each point represents an average of at least 3 samples cycled to failure. A logarithmic relationship, with a relatively high $\mathrm{R}^{2}$ value of 0.808 , was found between load and cycles to failure for samples strained at $254 \mathrm{~mm} / \mathrm{min}$.

Samples strained at $25.4 \mathrm{~mm} / \mathrm{min}$ with 0.9UTL had two orders of magnitude more cycles to failure than samples strained at $254 \mathrm{~mm} / \mathrm{min}$ with 0.9 UTL. This shows the LCF life of reinforced FFF parts are highly strain rate dependant.

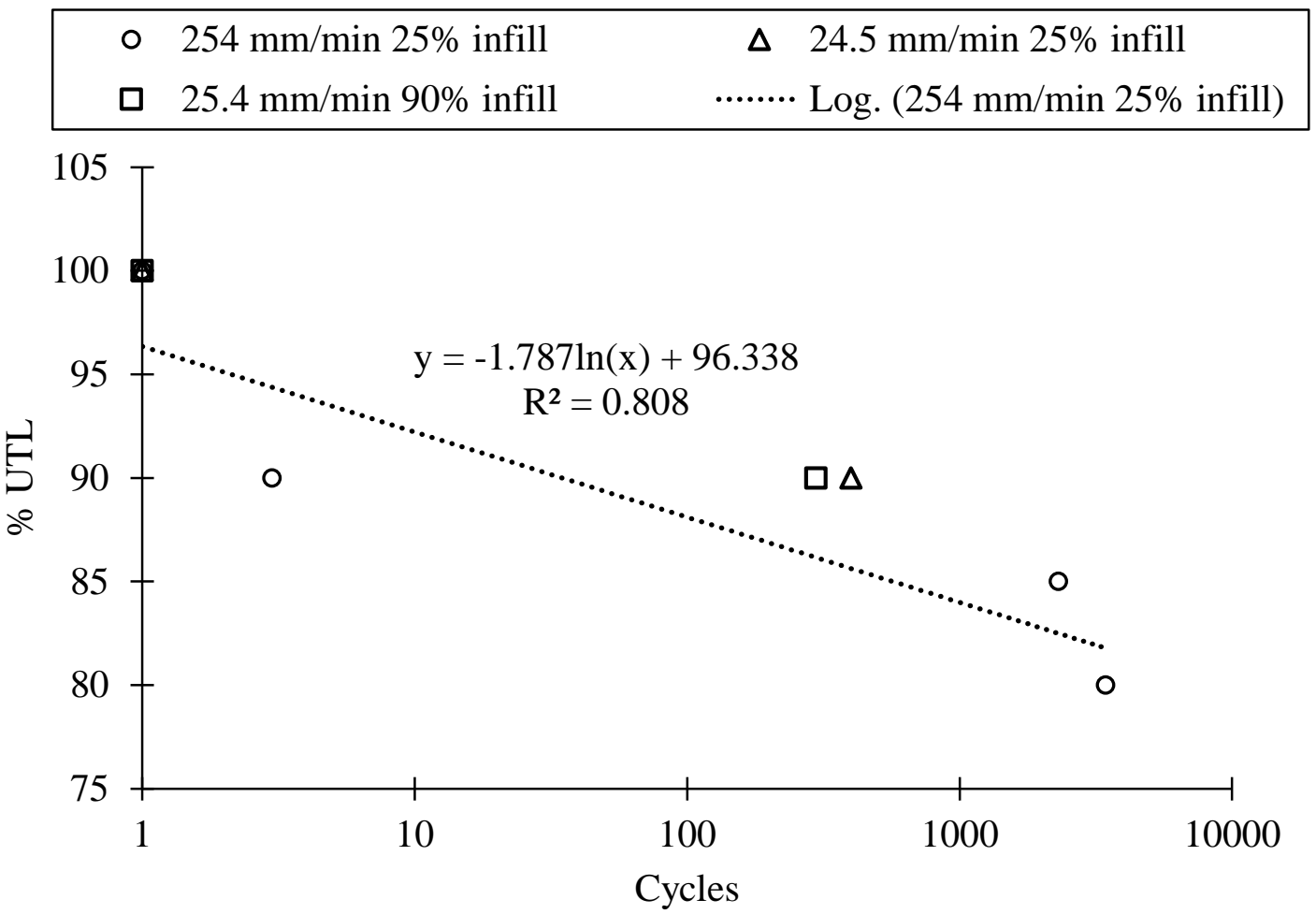

Figure 11: LCF life data for reinforced FFF parts with various normalised loads and strain rates. The stress ratio, $R$, is 0.2 .

No significant correlation was found between the tensile strength, elongation to failure, strain energy and FFF infill density.

Table 5. Average cycles to failure and elongation to failure, for LCF unreinforced DB samples.

\begin{tabular}{|c|c|c|c|c|c|c|}
\hline \multirow{2}{*}{$\begin{array}{c}\text { Strain } \\
\text { rate } \\
(\mathrm{mm} / \mathrm{min})\end{array}$} & \multicolumn{6}{|c|}{ Average low cycle fatigue test data } \\
\cline { 2 - 7 } & $\begin{array}{c}\text { Cycles to } \\
\text { failure }\end{array}$ & $\begin{array}{c}\text { Elongation } \\
\text { at failure } \\
(\mathrm{mm})\end{array}$ & $\begin{array}{c}\text { Cycles to } \\
\text { failure }\end{array}$ & $\begin{array}{c}\text { Elongation } \\
\text { at failure } \\
(\mathrm{mm})\end{array}$ & $\begin{array}{c}\text { Cycles } \\
\text { to failure }\end{array}$ & $\begin{array}{c}\text { Elongation } \\
\text { at failure } \\
(\mathrm{mm})\end{array}$ \\
\hline $25.4^{*}$ & - & - & - & - & 400 & 4.80 \\
\hline $25.4^{* *}$ & - & - & - & - & 297 & 4.74 \\
\hline $254^{*}$ & 3435 & 4.41 & 2306 & 5.32 & 3 & 5.05 \\
\hline
\end{tabular}

$*$ Infill density of $25 \%$.**Infill density of $90 \%$ 


\subsection{Reinforced Pulley Housing}

Three pulley housings were printed and reinforced using the methodology outlined in section 2. Tensile tests were carried out on two of the pulleys to determine an average UTL. A third sample was then tested using a LCF load profile, but failed at the start of the first relaxation phase. It appears inertia of the cross-head resulted in a maximum load higher than the specified 0.85UTL.The load/elongation profiles for all three samples can be seen in figure 12 .

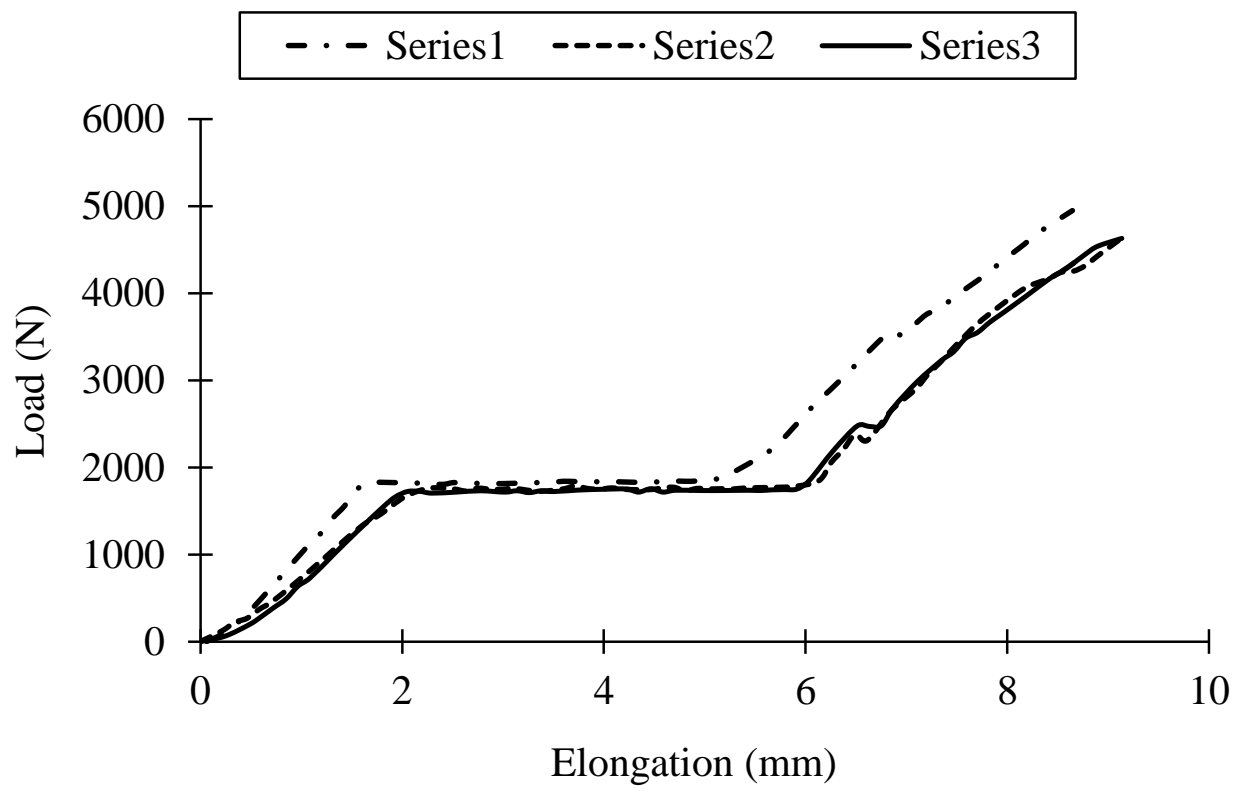

Figure 12: Load/elongation curves for reinforced pulley housings at $254 \mathrm{~mm} / \mathrm{min}$.

The load profiles for the pulley housings show a constant load phase which spans approximately $45 \%$ of the total elongation. This feature was not observed in any of the DB load curves or the previous pulley tensile tests carried out at $2.5 \mathrm{~mm} / \mathrm{min}$. The average UTL for the pulleys was found to be $4746 \mathrm{~N}$ which is similar to the UTL of the reinforced samples.

The PLA material was found to crack near access holes and preferentially fracture between build layers (Figure 13). The composite carbon fibre reinforcement failed with a ruptured appearance. 

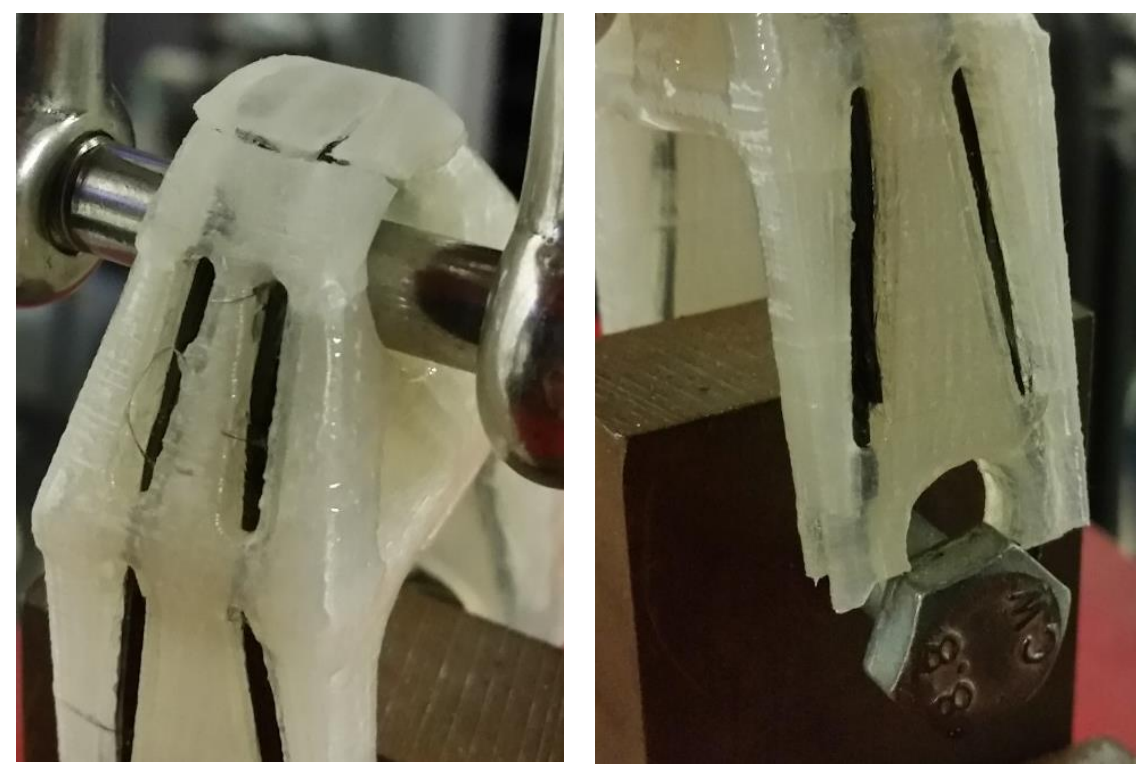

Figure 12: PLA and reinforcement fractures after high strain rate tensile loading.

\section{DISCUSSION}

PLA FFF parts were found to have short LCF lives with brittle fracture occurring on the order of 10 cycles at $0.8 \mathrm{UTL}$. Reinforcing FFF parts with $4.7 \%$ carbon fibre by mass, increased the ultimate tensile strength by a factor of $4(25.4 \mathrm{~mm} / \mathrm{min}$ strain rate $)$ and the LCF life by a factor of 428 ( $254 \mathrm{~mm} / \mathrm{min}$ strain rate). In the majority of cases the reinforced LCF samples fractured in the narrow section of the sample near an access hole. Initial cracks near the access holes in the first few cycles led to progressive delamination of the reinforcement from the inner surface of the channels. Incremental separation of the reinforcement from the PLA was clearly visible in the longer LCF tests. This separation coupled with growing cracks in the PLA eventually lead to fast fracture. The access holes proved to be significant stress concentrators, suggesting new methods of introducing the fibres are needed.

Variation in the cycles to failure for all LCF samples was found to be far greater than the variation in elongation to failure. Strain based failure criteria could offer a more accurate failure criteria than cycle based approaches.

The pulley housing load/elongation curves at high strains had remarkably different geometries from the low strain rate curves in Figure 3. They also differed from the DB samples which had near linear stress/strain profiles with similar strain rates. This suggests that the load/elongation relationship for reinforced FFF parts depends on both part geometry and strain rate. It is likely that dynamic loading of the pulley caused previously unseen rapid plastic deformation of the PLA until the reinforcement tightened and continued to resist elongation. This is supported by the fact the pulley had a strain at failure of approximately $18 \%$ compared to $4.7 \%$ for the DB sample at the same strain rate. An extensive study is required to further understand the interrelationship between strain rate and geometry.

The average UTL for the pulley housings was found to be comparable to the DB samples with similar strain rates. This is an important result as it shows that if equivalent quantities of carbon 
fibre are used and they are aligned with the $1^{\text {st }}$ principle stresses then you can expect similar UTLs regardless of the overall part geometry.

\section{CONCLUSIONS AND RECCOMENDATIONS}

The geometric complexity offered by AM allows for the design of parts with complex internal channels which may be filled with continuous fibre reinforcement. By routing the channels through regions of high Von Mises stress and aligning them with the $1^{\text {st }}$ and $2^{\text {nd }}$ principal stresses it is possible to gain the maximum advantage from the mechanical properties of the fibres.

This study investigated the tensile and LCF failure characteristics of unreinforced and reinforced FFF PLA parts for a range of strain rates and loads. The main findings are summarised as follows:

- The small (4\% by mass) addition of carbon fibre to FFF DB samples was found to increase tensile strength by $400 \%$ and LCF life by $42,800 \%$.

- Reinforced FFF parts exhibit logarithmic load-cycle relationships.

- High strain rates result in reduced LCF life and unpredictable failure modes.

- In all cases elongation to failure was found to vary less than cycles to failure.

- Access ports used to thread the carbon fibre into the parts act as stress concentrators, initiating crack formation and separation of the reinforcement from the PLA.

- The near linear load/elongation relationship of the DB samples was not replicated by the pulley housing at high strain rates.

- The UTL values for the DB samples were comparable to the pulley values.

Further studies are required to test other load types such as bending, torsion, impact loads, HCF and the effects of scale. Continuous fibre reinforced AM parts would also benefit from:

- Automated design of the reinforcement channels from FEA data.

- Improved methods of introducing the reinforcement.

- Cost analysis and eco-audits to compare the economics and environmental benefits of AM polymer composite parts with other manufacturing methods.

- The application of engineering coatings and metallic inserts to improve thermal resistance, friction and wear.

- The integration of condition monitoring capabilities.

Research is ongoing to test whether coatings can be used to significantly improve surface properties. In addition novel internal structures and infills are being investigated for their ability to improve the parts thermal properties.

\section{REFERENCES}

AFROSE, M. F., MASOOD, S., NIKZAD, M. \& IOVENITTI, P. Effects of build orientations on tensile properties of PLA material processed by FDM. Advanced Materials Research, 2014. Trans Tech Publ, 31-34. 
AFROSE, M. F., MASOOD, S. H., IOVENITTI, P., NIKZAD, M. \& SBARSKI, I. 2015. Effects of part build orientations on fatigue behaviour of FDM-processed PLA material. Progress in Additive Manufacturing, 1-8.

AHN, S. H., MONTERO, M., ODELL, D., ROUNDY, S. \& WRIGHT, P. K. 2002. Anisotropic material properties of fused deposition modeling ABS. Rapid Prototyping Journal, 8, 248-257.

BATDORF, S. 1982. Tensile strength of unidirectionally reinforced composites-I. Journal of reinforced plastics and composites, 1, 153-164.

BELLEHUMEUR, C., LI, L., SUN, Q. \& GU, P. 2004. Modeling of bond formation between polymer filaments in the fused deposition modeling process. Journal of Manufacturing Processes, 6, 170-178.

BHAT, C., BHAT, M. R. \& MURTHY, C. R. L. 2008. Characterization of Failure Modes in CFRP Composites - An ANN Approach. Journal of Composite Materials, 42, 257 276.

BRACKETT, D., ASHCROFT, I. \& HAGUE, R. Topology optimization for additive manufacturing. 22nd Annual international solid freeform fabrication symposium, 2011. 348-362.

BROOKS, H. \& MOLONY, S. Dramatically Increasing the Mechanical Properties of 3D Printed Parts via Continuous Fibre Reinforcement and Coatings. In: RENNIE, A., ed. 14th Rapid Design, Prototyping and Manufacturing Conference (RDPM 2015), 15 16th December 20152015 Loughborough, UK.

BROOKS, H. \& MOLONY, S. 2016. Design and evaluation of additively manufactured parts with three dimensional continuous fibre reinforcement. Materials \& Design, 90, 276283.

ES-SAID, O. S., FOYOS, J., NOORANI, R., MENDELSON, M., MARLOTH, R. \& PREGGER, B. A. 2000. Effect of Layer Orientation on Mechanical Properties of Rapid Prototyped Samples. Materials and Manufacturing Processes, 15, 107-122.

GARDAN, N. \& SCHNEIDER, A. Topological optimization of internal patterns and support in additive manufacturing. Journal of Manufacturing Systems.

GIBSON, I., ROSEN, D. \& STUCKER, B. 2010. Additive Manufactruing Technologies, Springer US.

HAMBALI, R. H., SMITH, P. \& RENNIE, A. 2012. Determination of the effect of part orientation to the strength value on additive manufacturing FDM for end-use parts by physical testing and validation via three-dimensional finite element analysis.

International Journal of Materials Engineering Innovation, 3, 269-281.

HARIK, V. M., KLINGER, J. R. \& BOGETTI, T. A. 2002. Low-cycle fatigue of unidirectional composites:: Bi-linear S-N curves. International Journal of Fatigue, 24, 455-462.

HARRIS, B. 2003. Fatigue in composites: science and technology of the fatigue response of fibre-reinforced plastics, Woodhead Publishing.

HASHIN, Z. \& ROTEM, A. 1973. A Fatigue Failure Criterion for Fiber Reinforced Materials. Journal of Composite Materials, 7, 448-464.

LEE, J. \& HUANG, A. 2013. Fatigue analysis of FDM materials. Rapid Prototyping Journal, 19, 291-299.

LU, L., SHARF, A., ZHAO, H., WEI, Y., FAN, Q., CHEN, X., SAVOYE, Y., TU, C., COHEN-OR, D. \& CHEN, B. 2014. Build-to-last: Strength to weight 3D printed objects. ACM Transactions on Graphics (TOG), 33, 97.

MAHAJAN, C. \& CORMIER, D. 2015. 3D Printing of Carbon Fiber Composites With Preferentially Aligned Fibers. Industrial and Systems Engineering Research Conference. 
MALLICK, P. K. 2007. Fiber-Reinforced Composites: Materials, Manufacturing, and Design, Third Edition, CRC Press.

MONTERO, M., ROUNDY, S., ODELL, D., AHN, S.-H. \& WRIGHT, P. K. Material characterization of fused deposition modeling (FDM) ABS by designed experiments. Proceedings of rapid prototyping and manufacturing conference, SME, 2001. 1-21.

NAMIKI, M., UEDA, M., TODOROKI, A., HIRANO, Y. \& MATSUZAKI, R. 2014. 3D Printing of Continuous Fibre Reinforced Plastic. Proceedings of the Society of the Advancement of Material and Process Engineering.

NING, F., CONG, W., QIU, J., WEI, J. \& WANG, S. 2015. Additive manufacturing of carbon fiber reinforced thermoplastic composites using fused deposition modeling. Composites Part B: Engineering, 80, 369-378.

RODRIGUEZ, J. F., THOMAS, J. P. \& RENAUD, J. E. 2000. Characterization of the mesostructure of fused-deposition acrylonitrile-butadiene-styrene materials. Rapid Prototyping Journal, 6, 175-186.

RODRíGUEZ, J. F., THOMAS, J. P. \& RENAUD, J. E. 2003. Design of Fused-Deposition ABS Components for Stiffness and Strength. Journal of Mechanical Design, 125, 545551.

SOOD, A. K., OHDAR, R. K. \& MAHAPATRA, S. S. 2010. Parametric appraisal of mechanical property of fused deposition modelling processed parts. Materials \& Design, 31, 287-295.

SUN, Q., RIZVI, G., BELLEHUMEUR, C. \& GU, P. 2008. Effect of processing conditions on the bonding quality of FDM polymer filaments. Rapid Prototyping Journal, 14, 72 80.

TYMRAK, B. M., KREIGER, M. \& PEARCE, J. M. 2014. Mechanical properties of components fabricated with open-source 3-D printers under realistic environmental conditions. Materials \& Design, 58, 242-246.

VAN DER KLIFT, F., KOGA, Y., TODOROKI, A., UEDA, M., HIRANO, Y. \& MATSUZAKI, R. 2015. 3D Printing of Continuous Carbon Fibre Reinforced ThermoPlastic (CFRTP) Tensile Test Specimens. Open Journal of Composite Materials, 6 , 18.

VILLALPANDO, L., EILIAT, H. \& URBANIC, R. J. 2014. An Optimization Approach for Components Built by Fused Deposition Modeling with Parametric Internal Structures. Procedia CIRP, 17, 800-805.

WOHLERS, T. 2016. Wohlers Report 2016.

ZIEMIAN, C., SHARMA, M. \& ZIEMIAN, S. 2012. Anisotropic mechanical properties of ABS parts fabricated by fused deposition modelling, INTECH Open Access Publisher.

ZIEMIAN, S., OKWARA, M. \& ZIEMIAN, C. W. 2015. Tensile and fatigue behavior of layered acrylonitrile butadiene styrene. Rapid Prototyping Journal, 21, 270-278.

ZWEBEN, C. 1968. Tensile failure of fiber composites. AIAA journal, 6, 2325-2331. 